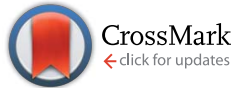

Cite this: RSC Adv., 2015, 5, 24705

Received 18th November 2014 Accepted 24th February 2015

DOI: 10.1039/c4ra14826f

www.rsc.org/advances

\title{
Amazing selectivity for Am(III) uptake by composite graphene oxide-PES polymeric beads prepared by phase inversion
}

\author{
Rajesh Bhikaji Gujar and Prasanta Kumar Mohapatra*
}

\begin{abstract}
Novel polyethersulphone (PES) based polymeric beads containing graphene oxide (GO), prepared by a phase inversion technique for the first time, were evaluated for actinide ion uptake from acidic feed solutions. The actinide ions studied were $\mathrm{Am}^{3+}, \mathrm{Pu}^{4+}, \mathrm{Th}^{4+}, \mathrm{UO}_{2}{ }^{2+}$ while $\mathrm{Eu}^{3+}$ was taken as a representative trivalent lanthanide ion. The feeds used for the uptake studies were unbuffered aqueous $\mathrm{pH}$ solutions and the observed trend was: $\mathrm{Am}^{3+} \sim \mathrm{Eu}^{3+} \gg \mathrm{UO}_{2}{ }^{2+} \sim \mathrm{Th}^{4+}>\mathrm{Pu}^{4+}$. The results were highly encouraging as $\mathrm{Am}^{3+}$ uptake was very high at $\mathrm{pH} \sim 5$ suggesting that the $\mathrm{GO}$ beads can be used for the remediation of low acidic radioactive effluents containing $\mathrm{Am}^{3+}$ ions. The metal sorption capacity for Am(III) at $\mathrm{pH} 4.0$ was found to be $1.22 \pm 0.07 \mathrm{mg} \mathrm{g}^{-1}$ of the GO resin whereas the $q_{\max }$ (the maximum predicted sorption capacity) obtained from the Langmuir isotherm was $1.72 \pm 0.07 \mathrm{mg} \mathrm{g}^{-1}$ of the GO resin. The sorption isotherm analysis was done by fitting the batch uptake data to the Langmuir, D-R and Freundlisch models. Column studies carried out with the GO-PES beads showed a breakthrough of Am(III) beyond $4 \mathrm{~mL}$. Elution profiles were obtained using $0.1 \mathrm{M} \mathrm{HNO}_{3}$ and about $20 \mathrm{~mL}$ was required for quantitative elution.
\end{abstract}

\section{Introduction}

Remediation of ground water contaminated with radioactive elements, especially, the long lived actinides, is one of the most challenging problems. ${ }^{1}$ There are heavy localized contaminations of ground water due to nuclear weapons testing, accidents involving space crafts such as the challenger or reactors such as Fukushima-Daiichi or Chernobyl. ${ }^{2,3}$ The radioactive waste management program involves immobilization of the waste oxides in glass matrices which are subsequently buried underground. Though the leaching rates are extremely low for the leakage of the radionuclides into the environment, there is a possibility of their release from the buried vitrified blocks due to earthquakes or leaching due to deformation of the glass due to phase incompatibility. In view of these factors, there is a need to develop efficient separation methods for the decontamination of ground water containing radioactive element ions, especially the actinide ions. Some of the decontamination techniques include treatment of the contaminated water with ion-exchange or membrane based separation methods., ${ }^{4,5}$

Recently, there are reports on carbon nano materials such as carbon nano tubes and graphene oxide (GO) being used for the treatment of radioactive waste water. ${ }^{6-8}$ These nano materials have high surface area and thus, have high metal ion uptake capacities. Out of these, GO are found to be the most promising

Radiochemistry Division, Bhabha Atomic Research Centre, Trombay, Mumbai-40o 085, India. E-mail: mpatra@barc.gov.in; Fax: +91-22-25505151 due to the possibility of functionalization with different groups including epoxy, hydroxyl and carboxyl moieties. ${ }^{9-11}$ A recent report has shown the use of GO for the sorption of actinides from aqueous solutions in the $\mathrm{pH}$ range of 1-11 with reasonably fast uptake kinetics. ${ }^{8}$ Though this study has shown very high sorption of metal ions such as $\mathrm{Pu}^{4+}$ and $\mathrm{Th}^{4+}$, there is a good possibility of dealing with hydrolyzed species at $\mathrm{pH}$ values as low as 1-2. Even $\mathrm{UO}_{2}{ }^{2+}$ and $\mathrm{Am}^{3+}$ are likely to get hydrolyzed in the $\mathrm{pH}$ range of 5-7 suggesting that there is a need to carry out studies in a more systematic manner. Furthermore, it is difficult to use the sorption data for effective development of a separation technique for actinides in view of the dispersible nature of the GO and the fine nano layers can hardly be handled efficiently in a column mode. Therefore, there was a need to prepare polymeric resin beads containing GO and to evaluate those for actinide ion uptake.

There have been reports on the use of polymeric resin beads with the extractants blended with the polymer and the resin beads prepared by a phase inversion technique to yield highly porous beads to have faster mass transfer rates. ${ }^{\mathbf{1 2 - 1 5}}$ It was thought of interest to prepare such beads containing GO in polyethersulphone (PES) as the polymer. In the present paper, the GO containing PES beads were prepared and characterized by various techniques including thermal analysis, SEM and were subsequently tested for the uptake of actinide ions viz., $\mathrm{UO}_{2}{ }^{2+}, \mathrm{Th}^{4+}, \mathrm{Pu}^{4+}$ and $\mathrm{Am}^{3+}$ from acidic $\mathrm{pH}$ feed solutions. The studies also included fitting the sorption data to various isotherm models such as Langmuir, Freundlich, and Dubinin- 
Radushkevich and finally, the column studies were carried out which included to obtain breakthrough and elution profiles for the possible application to contaminated water samples. In all these studies requiring macro concentrations of the metal ion, Eu carrier was used as a surrogate of the trivalent actinide in view of the large gamma ray dose coming from macro concentrations of Am.

\section{Experimental}

\subsection{Materials}

2.1.1 Reagents. Graphene oxide and polyether sulphone (PES) beads, procured from M/s J. K. Impex, Mumbai, were used as obtained. Chloroacetic acid (BDH), glacial acetic acid (Chemco Fine Chem, Mumbai), Spec pure $\mathrm{Eu}_{2} \mathrm{O}_{3}$ (John Baker), $N$-methyl-2-pyrrolidone or NMP (SD Fine Chem) and sodium hydroxide (SRL, Mumbai) were used without any further purification. All the other reagents were of AR grade and were used as received.

2.1.2 Radiotracers. Laboratory stocks of ${ }^{241} \mathrm{Am}$ and ${ }^{233} \mathrm{U}$ were freshly purified using ion-exchange separation methods ${ }^{\mathbf{1 6}}$ and the purities were checked by alpha-spectrometry. $\mathrm{Pu}$ (mainly ${ }^{239} \mathrm{Pu}$ ) was used from the laboratory stock after confirming the absence of its daughter products by $\alpha$ spectrometry. ${ }^{152} \mathrm{Eu}$ was obtained from BRIT, Mumbai and was used after checking its radiochemical purity. ${ }^{234}$ Th was obtained by freshly milking an extract of natural $U$ in Aliquat 336 by $6 \mathrm{M} \mathrm{HCl}$ and purifying the Th-radiotracer by a reported method. ${ }^{17}$ Valency of $\mathrm{Pu}$ was adjusted to the +4 state using reported methods. ${ }^{18,19}$

${ }^{241} \mathrm{Am},{ }^{152} \mathrm{Eu}$ and ${ }^{234} \mathrm{Th}$ were assayed by gamma ray spectrometry using a NaI(Tl) detector (Para Electronics) coupled to a multi-channel analyzer (ECIL, Mumbai). Pu and ${ }^{233} \mathrm{U}$ were assayed radiometrically using a LSC (liquid scintillation counting) system procured from Hidex, Finland using a toluene-based extractive scintillator cocktail (SRL, Mumbai).

\subsection{Methods}

2.2.1 Preparation of resin beads. The PES polymer solution containing GO was prepared by dissolving about $1 \mathrm{~g}$ of PES and $10 \mathrm{mg}$ of GO in NMP after sonicating for about 6-7 hours after which the solution appeared homogeneous. The polymer dope solution was dropped in to water through a needle attached to a syringe and the bead size was controlled to about 1-2 mm by adjusting the gap between the needle and the water surface. The details of the phase inversion have been reported in a previous publication. ${ }^{20}$ The GO containing PES polymer beads were washed with distilled water followed by drying in an oven under vacuum for $24 \mathrm{~h}$ at $70{ }^{\circ} \mathrm{C}$.

2.2.2 Characterization of the resin. The resin beads were characterized by thermogravimetric analysis using Netzsch Thermobalance (Model: STA 409 PC Luxx), at a heating rate of $10{ }^{\circ} \mathrm{C} \mathrm{min}^{-1}$, in Ar atmosphere. The surface area analysis was done by BET while the surface morphology was analyzed by taking SEM pictures using a Stereoscan 100 Cambridge model operating at $15 / 25 \mathrm{kV}$ with a magnification of $50-70 \times$ at a working distance of $15 \mathrm{~mm}$ at a tilt angle of $45^{\circ}$ after giving a
$15 \mathrm{~nm}$ coating of gold was using a Balzer's coating unit (model: CEA 30).

2.2.3 Batch sorption studies. The actinide ion uptake studies were carried out in two ways. The $K_{\mathrm{d}}$ values were obtained by carrying out uptake experiments by equilibrating about 15-20 mg of the GO-PES beads taken in leak-tight stoppered Pyrex tubes containing about $1 \mathrm{~mL}$ of the aqueous phase at the given $\mathrm{pH}$ and spiked with the requisite amount of a given radiotracer in a thermostated water bath maintained at $25 \pm$ $0.1^{\circ} \mathrm{C}$. The aqueous solutions with varying $\mathrm{pH}$ were prepared by first preparing the solutions at higher $\mathrm{pH}$ (for example, at $\mathrm{pH}$ 5.5) and subsequently adjusting the $\mathrm{pH}$ to the lower values by the addition of dilute $\mathrm{HNO}_{3}$ solution. In some studies, buffered solutions were used; for example, chloroacetate buffer $(0.05 \mathrm{M})$ was used for adjusting the $\mathrm{pH}$ from 2.5 to 3.8 and acetate buffer $(0.05 \mathrm{M})$ was used in the $\mathrm{pH}$ region of 4.0 to 5.5 . Suitable aliquots (usually $100 \mu \mathrm{L}$ ) were removed subsequently which were assayed radiometrically for the metal ion concentration as mentioned above. From the concentration of the radionuclide before and after equilibration, termed as $C_{\mathrm{o}}$ and $C_{\text {eq }}$, respectively the $K_{\mathrm{d}}$ (weight distribution coefficient) values were calculated using the following expression:

$$
K_{\mathrm{d}}=\left[\frac{\left(C_{\mathrm{o}}-C\right)}{C_{\mathrm{o}}}\right] \frac{V}{W}
$$

where, $V$ and $W$ are the volume of the aqueous phase (in $\mathrm{mL}$ ) and the weight of the resin (in g), respectively. $\mathrm{pH}$ of the aqueous phase was adjusted prior to the batch sorption experiments and final pH (after equilibration) values were also measured and are used for all data presentations and calculations. Usually, the differences in the $\mathrm{pH}$ values of the aqueous phases before and after equilibration were large (in $\mathrm{pH}$ values in the range of 3.5-5) in case of experiments involving unbuffered aqueous solutions while there were marginal variations in case of buffered solutions. All batch sorption experiments were carried out in duplicate and the mass balance was found to be within $\pm 5 \%$.

Batch sorption experiments to obtain the extraction isotherms (vide infra) were carried out only for the trivalent metal ions using Eu carrier $\left(100 \mathrm{mg} \mathrm{L}^{-1}\right)$. The experiments were carried out by equilibrating about $50 \mathrm{mg}$ of the GO-PES beads in a stoppered conical flask containing $20 \mathrm{~mL}$ of the Eu carrier solution (used as a surrogate of Am) spiked with ${ }^{241} \mathrm{Am}$ radiotracer. The saturation batch uptake capacity of the resin was calculated by carrying out the equilibration for 48 hours to ensure attainment of equilibrium.

2.2.4 Column studies. The column studies using the GO-PES beads were carried out in the usual manner by packing a glass column $(10 \mathrm{~mm}$ diameter $\times 100 \mathrm{~mm}$ height $)$ with about $0.53 \mathrm{~g}$ of the resin material. The column was fitted with a frit permeable to water flow and also a stop cock to control the flow rate. In view of low density of the beads, extra care was taken to ensure no air gap in the resin bed filled with water. The column containing the GO-PES beads had a height of $6.1 \mathrm{~cm}$ and a bed volume of about $4.8 \mathrm{~cm}^{3}$ which remained constant (within $\pm 0.5 \%)$ over the loading and elution experiments suggesting negligible swelling. The flow rate was controlled to about $0.3 \pm$ 
$0.02 \mathrm{~mL}$ per minute using a stop cock. The feed solution for the column studies was the Eu carrier solution spiked with ${ }^{241} \mathrm{Am}$ as mentioned above and the $\mathrm{pH}$ of the feed was adjusted to 4.0. Elution of the loaded metal ion was done by passing $0.5 \mathrm{M}$ $\mathrm{HNO}_{3}$ solution at the flow rate mentioned above. The loading and elution profiles were obtained by first collecting successive

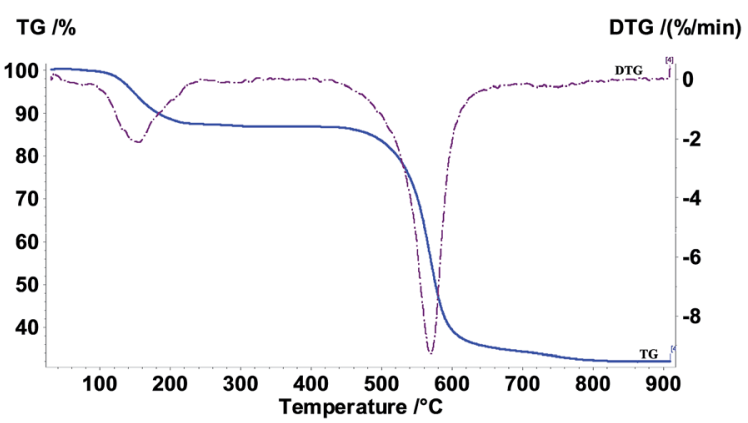

Fig. 1 Thermogram of decomposition of the composite GO-PES beads in air. Heating rate: 10 degree per minute.

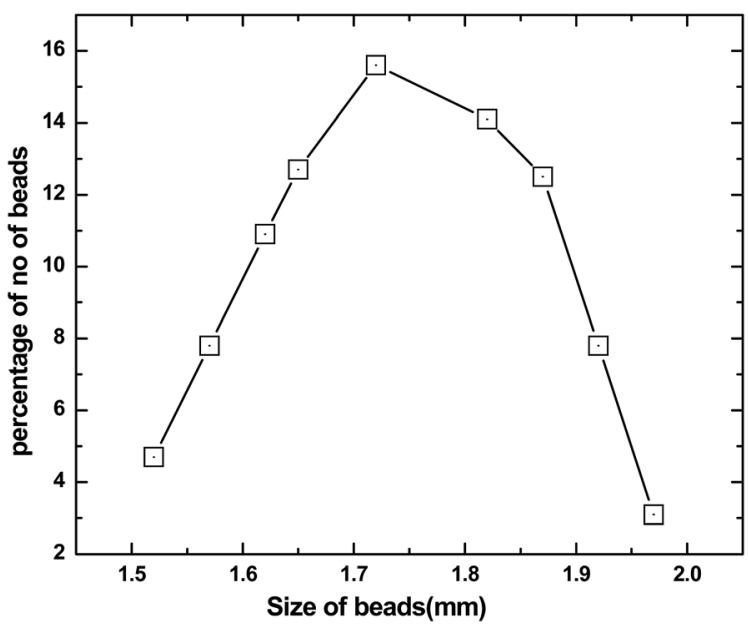

Fig. 2 Size distribution plot of the composite GO-PES beads.
$1 \mathrm{~mL}$ effluent samples from the column in separate vials and then assaying about $100 \mu \mathrm{L}$ sample from each vial radiometrically by gamma ray counting (vide supra). All the chromatographic runs were carried out at ambient temperature (24 \pm $0.5{ }^{\circ} \mathrm{C}$ ) and the results were reproducible within an error limit of $\pm 5 \%$.

\section{Results and discussion}

\subsection{Characterization of the GO-PES resin beads}

The gray colored resin beads appeared spherical and the size of the beads were found to be in the range of 1.5-2.0 $\mathrm{mm}$. The size distribution data are presented in Fig. 1 which suggested average size of $1.72 \mathrm{~mm}$. The BET analysis of the polymeric resin beads indicated an average surface area of $11.4 \mathrm{~m}^{2} \mathrm{~g}^{-1}$. The thermogravimetric analysis of the beads suggested two distinct weight losses, one starting at $120^{\circ} \mathrm{C}$ and the other in the range of $500-600{ }^{\circ} \mathrm{C}$ (Fig. 2). While the $15 \%$ weight loss at $120{ }^{\circ} \mathrm{C}$ is attributed to loss of moisture trapped in the beads, the $50-55 \%$ weight loss in the range of $500-600{ }^{\circ} \mathrm{C}$ was due to weight loss due to PES as reported in a previous study. ${ }^{21}$ In view of only $1 \%$ GO present in the polymeric beads, the weight loss due to GO is not seen. The FT-IR spectra of the resin beads are presented in Fig. 3. Though there are several bands corresponding to PES and NMP, characteristic peaks of GO are also seen, for example, the carbonyl group (1673 $\mathrm{cm}^{-1}$ ), $-\mathrm{OH}$ group of the carboxylic acid functional group $\left(3097 \mathrm{~cm}^{-1}\right)$ and the benzene ring $\left(1581 \mathrm{~cm}^{-1}\right)$. The surface morphology of the polymeric bead and its cross section (after carefully cutting the bead in to half) were analyzed by SEM using gold coating (vide supra) and the magnified micrographs $(50 \times)$ are presented in Fig. 4 .

\subsection{Sorption kinetic studies}

The kinetics of Am(III) uptake from aqueous solutions (unbuffered $\mathrm{HNO}_{3}$ solution at $\mathrm{pH}$ 4) was studied using the GO-PES polymeric beads by equilibrating the tubes for varying equilibration times after which a known aliquot was removed and assayed radiometrically. It was observed that the attainment of

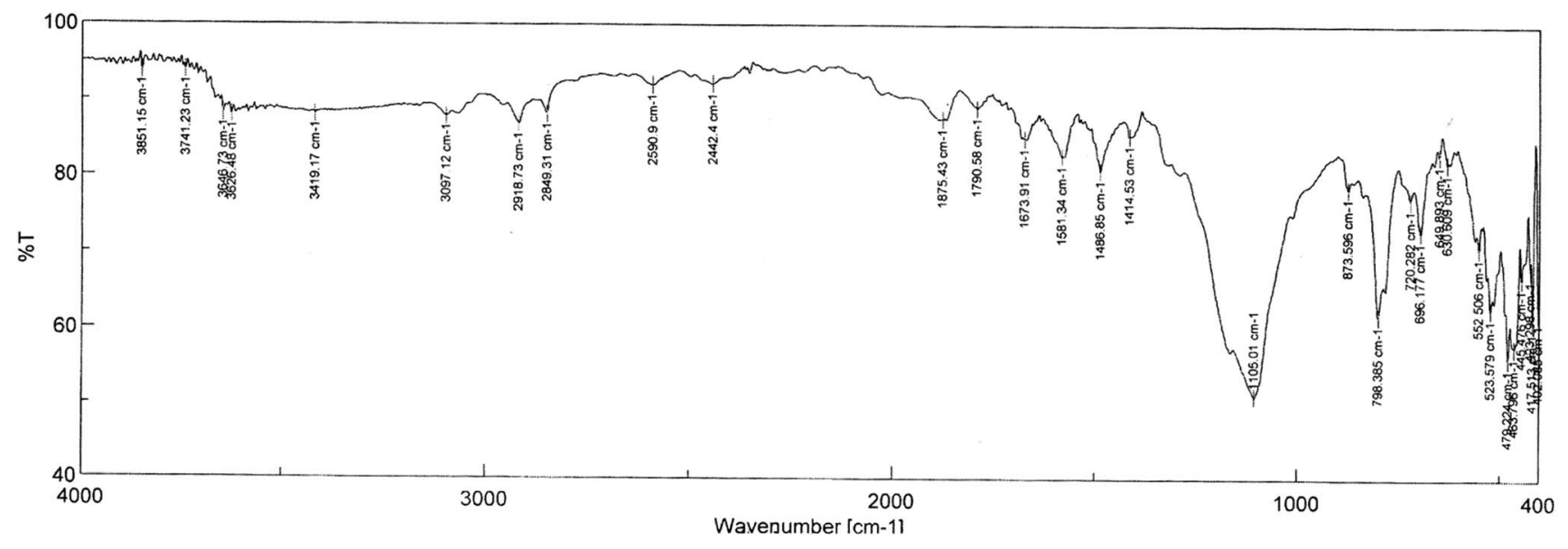

Fig. 3 FT-IR spectra of the GO-PES beads. 


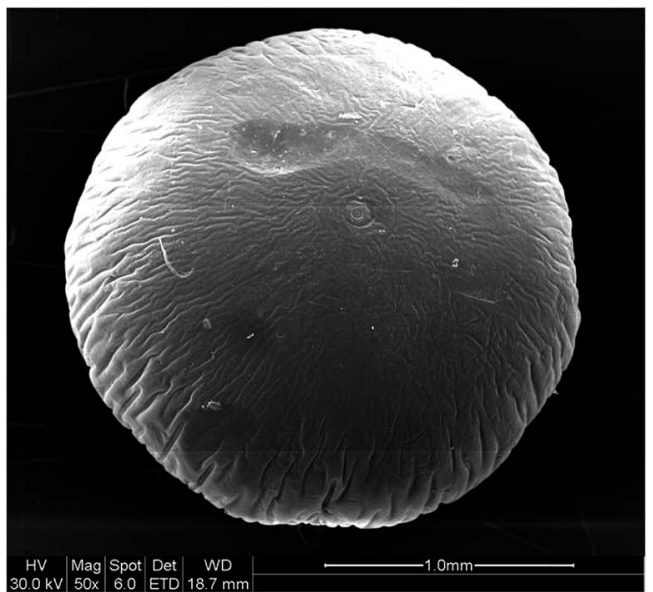

(a)

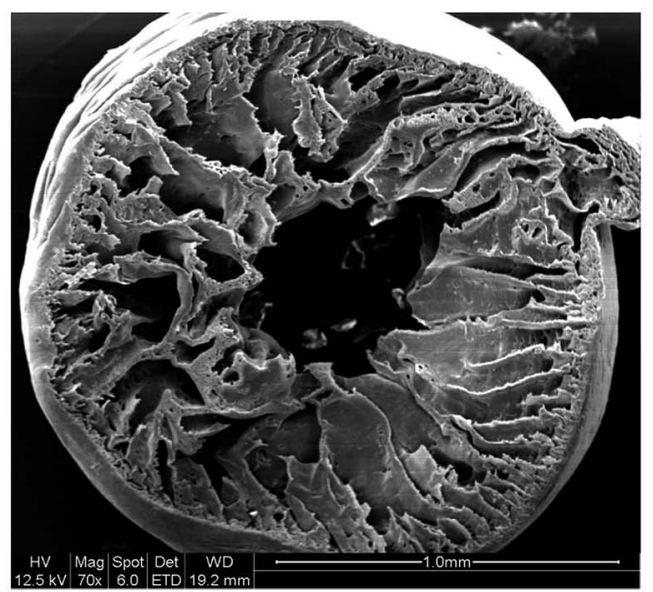

(b)

Fig. 4 SEM micrographs of the (a) whole and (b) half dissected GOPES beads.

equilibrium was rather slow and it took about $2-2.5 \mathrm{~h}$ for attaining a steady $K_{\mathrm{d}, \mathrm{w}}$ value. This was rather surprising as similar polymeric beads containing Cyanex 923 as the extractant has showed much faster uptake kinetics as only 2030 minutes were needed. ${ }^{20}$ On the other hand, Romanchuk, et al., have reported Am(III) uptake using GO dispersed in water at a much faster rate as less than 5 minutes were needed from an aqueous solution of $\mathrm{pH} 3.63 .{ }^{8}$ Though exact reason for the slow uptake kinetics is not known, it may be presumed that the dispersed GO can have better mass transfer as compared to the composite GO-PES beads. Also, the hydrophobic PES beads may have slower mass transfer rates due to slow diffusion rates due to poor wetting of the polymeric beads.

\subsection{Effect of the aqueous phase $\mathrm{pH}$}

Am(III) ion uptake studies were also carried out as a function of the aqueous phase $\mathrm{pH}$ by using unbuffered as well as buffered (using chloroacetate as well as acetate buffers) solutions. The buffer solutions were of rather low concentration $(0.05 \mathrm{M})$, which was adequate to arrest $\mathrm{pH}$ fluctuations while reducing

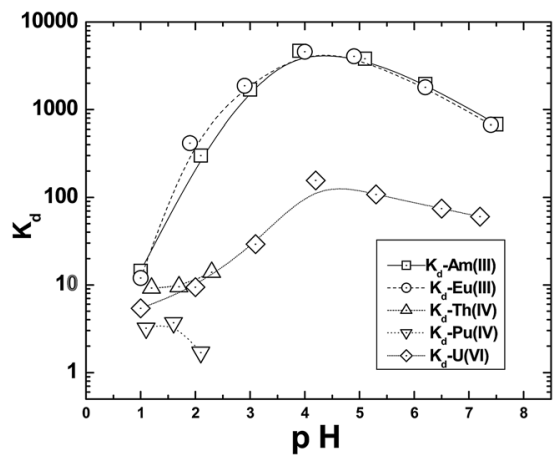

Fig. 5 Plots of the uptake of $\mathrm{Am}(\mathrm{III}), \mathrm{Eu}(\mathrm{III}), \mathrm{UO}_{2}{ }^{2+}, \mathrm{Th}(\mathrm{IV})$ and $\mathrm{Pu}(\mathrm{IV})$ as a function of aqueous phase $\mathrm{pH}$.

the aqueous complexation of the metal ions which would affect the $K_{\mathrm{d}}, \mathrm{w}$ values significantly. The sorption data suggested an increase up to a $\mathrm{pH}$ value of 4 where, very high $K_{\mathrm{d}, \mathrm{w}}$ values (>4500) were obtained (Fig. 5). There was a slow decline in the $K_{\mathrm{d}, \mathrm{w}}$ values beyond $\mathrm{pH} 4$ which may be attributed to contributions from hydrolysis of the metal ions. Though there have been reports of hydrolysis constants of Am(III) being >6, there are several reports on much lower hydrolysis constants. ${ }^{22}$ The low hydrolysis constant of Am(III) has been corroborated by a subsequent report showing significant adsorption of Am tracer on to glass vials at $\mathrm{pH}$ values of 5 and above. ${ }^{23}$ Similar loss in mass balance was also observed in the present case and in view of this, the Pyrex glass tubes were treated with dichlorodimethyl silane (DCDMS) to reduce material balance loss due to the sorption of Am tracer on to the glass surface. ${ }^{24}$ It may be concluded from this that the decrease in Am(III) $K_{\mathrm{d}, \mathrm{w}}$ values at higher $\mathrm{pH}$ values is due to hydrolysis of metal ion leading to relatively poor uptake by the GO-PES polymeric beads. The studies carried out using the buffered aqueous solutions have shown significant decrease in the distribution coefficient values in the entire $\mathrm{pH}$ range, the $K_{\mathrm{d}}$ value at $\mathrm{pH} 4$ being $<1000$. This could be attributed to the complexation of the radio tracer with the chloroacetate/acetate ions.

Another set of experiments carried out using the aqueous solutions at varying pH but containing $1 \mathrm{M} \mathrm{NaNO}_{3}$ indicated even lower metal ion sorption and a peak $K_{\mathrm{d}, \mathrm{w}}$ value of 260 was obtained at $\mathrm{pH}$ 5.0. Though the lower $K_{\mathrm{d}, \mathrm{w}}$ value may be attributed to nitrate ion complexation, the shift of the peak value can not be clearly explained.

The uptake of actinide ions such as $\mathrm{Th}(\mathrm{Iv}), \mathrm{Pu}(\mathrm{Iv})$ and $\mathrm{UO}_{2}{ }^{2+}$ was investigated using the polymeric beads and the data are presented in Fig. 5. In view of hydrolysis of the tetravalent ions such as $\mathrm{Pu}(\mathrm{Iv})$ and $\mathrm{Th}(\mathrm{rv})$, the uptake studies were limited to $\mathrm{pH}$ 2. The radioactive wastes containing fission product nuclides invariably contain a large fraction of lanthanides which are chemically similar to the trivalent minor actinides such as Am(III). Therefore, the uptake of a trivalent lanthanide ion, $\mathrm{Eu}(\mathrm{III})$, was also investigated under conditions identical to the Am(III) uptake study. The trend of metal ion uptake was: $\mathrm{Am}^{3+} \sim$ $\mathrm{Eu}^{3+} \gg \mathrm{UO}_{2}{ }^{2+} \sim \mathrm{Th}^{4+}>\mathrm{Pu}^{4+}$. The results obtained in the present study are in sharp contrast to those reported by dispersed GO solutions where, the tetra-valent metal ions were 
nearly quantitatively extracted at $\mathrm{pH} 2$ while $\mathrm{U}$ uptake was $<10 \%{ }^{8}$

\subsection{The sorption isotherms}

The uptake data obtained using Eu carrier solution (spiked with ${ }^{241} \mathrm{Am}$ tracer) at $\mathrm{pH} 4.0$ and $25{ }^{\circ} \mathrm{C}$ were fitted to different isotherm models such as the Langmuir, D-R and Freundlich. The Langmuir sorption isotherm ${ }^{25}$ can be given by the following expression,

$$
\frac{C_{\mathrm{eq}}}{q}=\frac{[1]}{b q_{\max }}+\frac{C_{\mathrm{eq}}}{q_{\max }}
$$

where, $C_{\text {eq }}$ is the equilibrium concentration of $\mathrm{Eu}^{3+}$ in the aqueous phase, $q$ is the amount of Eu sorbed onto the GO-PES beads while $q_{\max }$ and $b$ are the maximum amount of Eu sorbed at saturation and the sorption coefficient $\left(\mathrm{L} \mathrm{mg}^{-1}\right)$, respectively. The plot of $C_{\text {eq }} / q v s$. $C_{\text {eq }}$ is presented in Fig. 6 and as shown deviations from linearity was observed suggesting that the Langmuir isotherm may not be applicable for the sorption of $\mathrm{Eu}$ onto the GO-PES polymeric beads. The Langmuir constants $q_{\max }$ and $b$ obtained from the linear fit are listed in Table 1. The calculated value of $q_{\max }$ of $1.72 \pm 0.03 \mathrm{mg} \mathrm{g}^{-1}$ obtained from the slope of the plot was about $50 \%$ higher than the experimentally obtained data of $1.22 \pm 0.07 \mathrm{mg} \mathrm{g}^{-1}$. The Langmuir constant, $b$, however, was found to lie between 0 and 1 suggesting that sorption process is favorable. ${ }^{26}$

The Eu uptake data using the carrier solution were also fitted to the Freundlich sorption isotherm model, which assumes

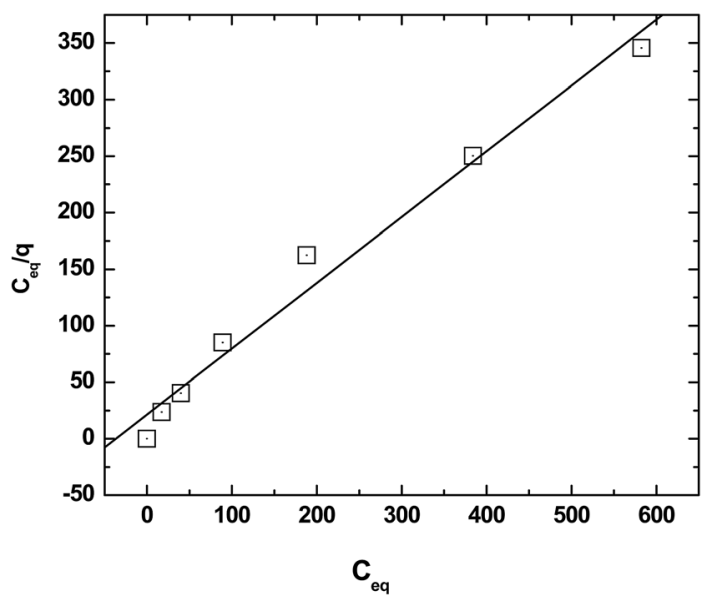

Fig. 6 Langmuir plot for the sorption of Am(III) onto the composite $\mathrm{GO}-\mathrm{PES}$ beads. Aqueous phase: unbuffered $\mathrm{pH} 4$ solutions; temperature: $25^{\circ} \mathrm{C}$. multi layer sorption mechanism given by the linear form of equation, ${ }^{27,28}$

$$
\log \left(\frac{x}{m}\right)=\log K_{\mathrm{f}}+\frac{1}{n} \log C_{\mathrm{eq}}
$$

where, $C_{\text {eq }}$ is the equilibrium Eu concentration in the feed while $x / m$ represents the amount of Eu sorbed per unit mass of the GO-PES beads. $K_{\mathrm{f}}$ is a constant dependent on the sorption capacity while $n$ is related to the Eu sorption intensity. As shown in Fig. 7, the plots of $\log (x / m)$ versus $\log C_{\text {eq }}$ appeared reasonably linear $\left(R^{2}=0.979\right)$ compared to the non-linear Langmuir plot (vide supra).

The batch sorption data were also fitted to the DubininRadushkevich (D-R) isotherm equation as given below, ${ }^{29}$

$$
\ln q=\ln X_{\mathrm{m}}-\beta \varepsilon^{2}
$$

where $X_{\mathrm{m}}$ is the maximum sorption capacity, $\beta$ is related to the mean sorption energy, and $\varepsilon$ is the Polanyi potential, ${ }^{30}$ which is expressed by the following equation,

$$
\varepsilon=R T \ln \left(1+\frac{1}{C_{\mathrm{eq}}}\right)
$$

where $R$ is the gas constant and $T$ is the absolute temperature. The semi log linearized plot (Fig. 8) appeared to have reasonably good fit $\left(R^{2}=0.981\right)$. The D-R constants $\beta$ and $X_{\mathrm{m}}$ are calculated from the equations given above as $-(2.54 \pm 0.25) \times 10^{-3} \mathrm{~mol}^{2}$ $\mathrm{kJ}^{-2}$ and $0.018 \mathrm{mmol} \mathrm{g}^{-1}$ (Table 1 ). $\beta$ is also expressed as:

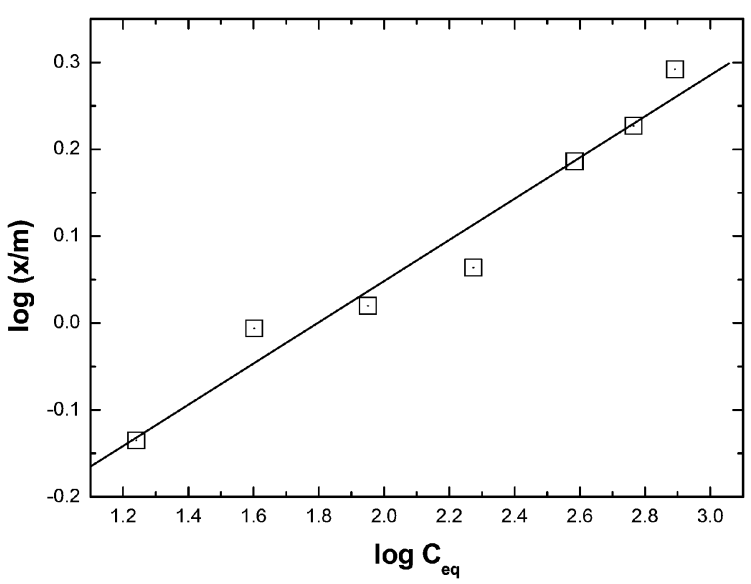

Fig. 7 Freundlich plot for the sorption of Am(III) onto the composite $\mathrm{GO}-\mathrm{PES}$ beads. Aqueous phase: unbuffered $\mathrm{pH} 4$ solutions; temperature: $25^{\circ} \mathrm{C}$.

Table 1 Parameters obtained from the different linearized form of sorption isotherms

\begin{tabular}{lll}
\hline Isotherm & Plot & Parameters \\
\hline Langmuir & $C_{\mathrm{eq}} / q_{\mathrm{t}} v s . C_{\mathrm{eq}}$ & $q_{\mathrm{max}}=1.72 \mathrm{mg} \mathrm{g}^{-1}( \pm 0.03) ; b=0.08 \mathrm{~L} \mathrm{mg}{ }^{-1}( \pm 0.01)$ \\
Freundlich & $\log q_{\mathrm{e}} v s . C_{\mathrm{eq}}$ & $K_{\mathrm{f}}=0.375( \pm 0.04) ; n=4.21( \pm 0.02)$ \\
D-R & $\ln q_{\mathrm{t}} v s . \varepsilon^{2}$ & $X_{\mathrm{m}}=0.018 \mathrm{mmol} \mathrm{g}^{-1} ; E=1 / 2 \beta^{0.5}\left(\mathrm{slope}^{2}=14.03 \mathrm{~kJ} \mathrm{~mol}^{-1}\right.$
\end{tabular}




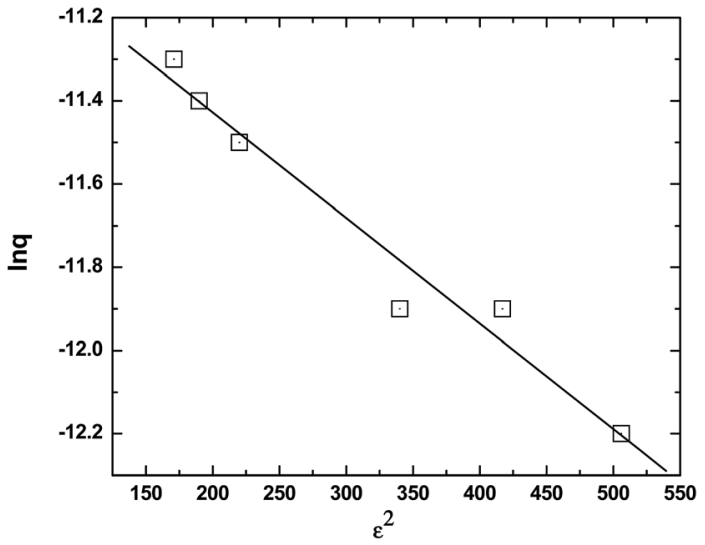

Fig. $8 \quad D-R$ isotherm for the sorption of $A m($ III) onto the composite GO-PES beads. Aqueous phase: unbuffered $\mathrm{pH} 4$ solutions; temperature: $25^{\circ} \mathrm{C}$.

$$
E=\frac{1}{\sqrt{-2 \beta}}
$$

where, $E$ is the mean free energy $\left(\mathrm{kJ} \mathrm{mol}^{-1}\right)$ of sorption and was calculated to be $14.03 \mathrm{~kJ} \mathrm{~mol}^{-1}$ which indicated to be a chemisorption process. ${ }^{31}$

\subsection{Column studies}

The column studies were carried out using a glass column containing the GO-PES beads the details of which are mentioned above. The column was conditioned by keeping under the $\mathrm{pH} 4$ solutions overnight. The carrier solution containing $0.1 \mathrm{~g} \mathrm{~L}^{-1} \mathrm{Eu}$ carrier and spiked with ${ }^{241} \mathrm{Am}$ radiotracer was passed through the column at a flow rate of $0.3 \mathrm{~mL}$ per minute and $1 \mathrm{~mL}$ fractions were separately collected in vials. $100 \mu \mathrm{L}$ aliquots were taken from each vial and were counted for $\mathrm{Eu}$ breakthrough. The breakthrough profile of $\mathrm{Eu}$ is plotted in Fig. 9 where the concentration of Eu was plotted in place of

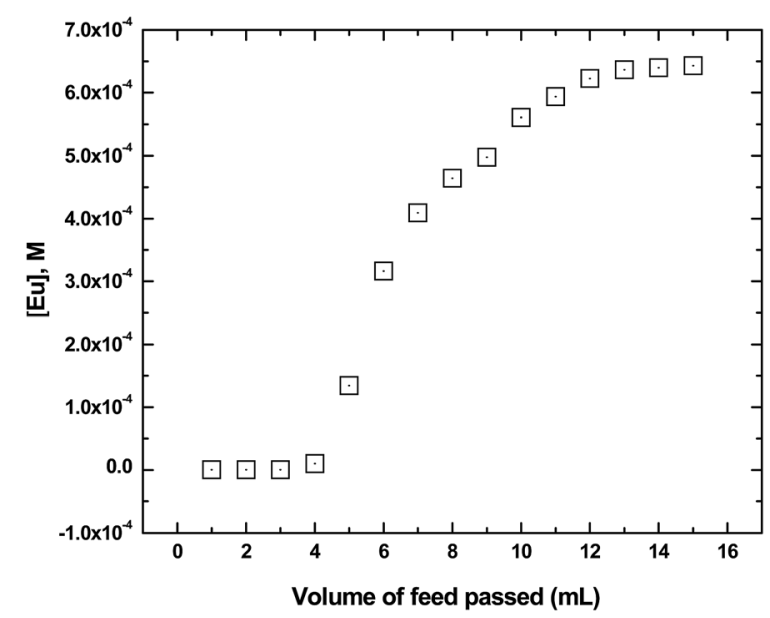

Fig. 9 Breakthrough profile of Am(III) while loading to a column containing the composite GO-PES beads. Feed: $100 \mathrm{mg} \mathrm{L}^{-1}$ Eu carrier in unbuffered $\mathrm{pH} 4$ solution; temperature: $25^{\circ} \mathrm{C}$. Flow rate: $0.3 \mathrm{~mL}$ per minute.

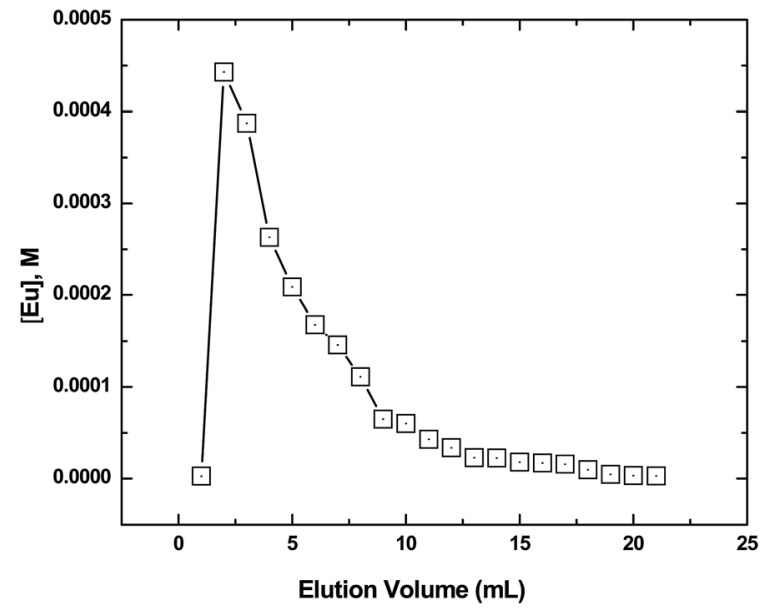

Fig. 10 Elution profile of Am(III) from the column containing the composite GO-PES beads. Eluent: $0.5 \mathrm{M} \mathrm{HNO}_{3}$; temperature: $25^{\circ} \mathrm{C}$. Flow rate: $0.3 \mathrm{~mL}$ per minute.

count rate in order to give a more realistic picture. As seen from the figure, the breakthrough occurred after passing only $4 \mathrm{~mL}$ of the Eu carrier solution indicating a breakthrough capacity of $0.755 \mathrm{mg} \mathrm{g}^{-1}$ or 0.005 millimoles per gram of the GO-PES polymeric beads. The capacity under dynamic condition is almost $62 \%$ of the saturation capacity of the beads experimentally determined (vide supra) which is easy to understand.

The loaded Eu was subsequently eluted using $0.5 \mathrm{M} \mathrm{HNO}_{3}$ and the elution profile is presented in Fig. 10. The elution pattern showed a broad tailing and about $20 \mathrm{~mL}$ was needed for quantitative $(>99 \%)$ recovery of the metal ion. Actinide ions such as Th(Iv), U(vI) and $\mathrm{Pu}(\mathrm{vI})$ are expected not to be loaded significantly on to the column in view of significantly lower $K_{\mathrm{d}}$ values (Fig. 5). The results are encouraging as the loading and elution of $\mathrm{Am}(\mathrm{III})$ can be carried out using relatively mild conditions (no complexing agent or strong acid solutions were used) and suggested that the GO-PES polymeric beads can possibly be used for the remediation of water contaminated with Am(III) ions.

\section{Conclusions}

PES based composite polymeric beads with 1\% GO were evaluated for the uptake of actinide ions such as Am(III), Th(IV), $\mathrm{Pu}(\mathrm{Iv})$ and U(vI). Though U(VI) was weakly sorbed, the tetravalent actinide ions were very poorly taken up by the beads. On the other hand, Am(III) and Eu(III) were sorbed very strongly with $K_{\mathrm{d}, \mathrm{w}}$ values $>4500$. The sorption isotherm studies have indicated that the uptake data fitted rather well to the Freundlisch and D-R models rather than the Langmuir model. The column studies yielded encouraging results as only $1 \%$ GO beads gave breakthrough of Eu from a feed containing $0.1 \mathrm{~g} \mathrm{~L}^{-1} \mathrm{Eu}$ carrier after about one column bed volume which gives a scope for scaling up with incorporating higher fraction of GO. The major disadvantage of the polymeric beads containing GO appeared to be the rather slow uptake kinetics as it took nearly $2-2.5 \mathrm{~h}$ to obtain equilibrium distribution coefficient values. It is 
proposed to use hydrophilic polymeric materials for preparation of analogous resin beads to enable faster mass transfer, which may be helpful in faster processing of actual contaminated water.

\section{Acknowledgements}

The authors are thankful to Dr A. Goswami, Head, Radiochemistry Division for his keen interest and support.

\section{References}

1 IAEA Technical Report Series 442, Remediation of sites with mixed contamination of radioactive and other hazardous substances, IAEA, 2006.

2 R. J. Silva and H. Nitsche, Radiochim. Acta, 1995, 70/71, 377396.

3 Special Fukushima Review session. Goldschmidt 2011 Earth, Life and Fire, Prague, Czech Republic, August 14-19, abstract published in Mineral Magazine 2011, 75(3).

4 IAEA Technical Report Series 442, Application of Ion Exchange Processes for the Treatment of Radioactive Waste and Management of Spent Ion Exchangers, IAEA, 2002.

5 D. Rana, T. Matsuura, M. A. Kassim and A. F. Ismail, Desalination, 2013, 321, 77-91.

6 F. Belloni, C. Kutahyali, C. C. Rondinella, P. Carbol, T. Wiss and A. Mangione, Environ. Sci. Technol., 2009, 43, 1250-1255. 7 P. Wang, US Patent No. 8343450, 2013.

8 A. Y. Romanchuk, A. S. Slesarev, S. N. Kalmykov, D. V. Kosynkint and J. M. Tour, Phys. Chem. Chem. Phys., 2013, 15, 2321-2327.

9 D. C. Marcano, D. V. Kosynkin, J. M. Berlin, A. Sinitskii, Z. Sun, A. Slesarev, L. B. Alemany, W. Lu and J. M. Tour, ACS Nano, 2010, 4, 4806-4814.

10 A. Dimiev, D. V. Kosynkin, L. B. Alemany, P. Chaguine and J. M. Tour, J. Am. Chem. Soc., 2012, 134, 2815-2822.

11 C. J. Madadrang, H. Y. Kim, G. H. Gao, N. Wang, J. Zhu, H. Feng, M. Gorring, M. L. Kasner and S. F. Hou, ACS Appl. Mater. Interfaces, 2012, 4, 1186-1193.
12 A. Figoli, J. Hoinkis, A. Criscuoli, C. Franz, M. de Rycke, C. Block, S. A. Deowan, R. Islam and E. Drioli, J. Harbin Inst. Technol., 2012, 19, 63-66.

13 A. Figoli, G. De Luca, E. Longavita and E. Drioli, Sep. Sci. Technol., 2007, 42, 2809-2827.

14 C. Dwivedi, S. K. Pathak, M. Kumar, S. C. Tripathi and P. N. Bajaj, RSC Adv., 2013, 3, 22102-22110.

15 S. K. Pathak, S. C. Tripathi, K. K. Singh, A. K. Mahtele, M. Kumar and P. M. Gandhi, J. Hazard. Mater., 2014, 278, 464-473.

16 P. K. Mohapatra, Ph. D. thesis, University of Bombay, 1993.

17 P. Thakur, R. Veeraraghavan, P. K. Mohapatra, V. K. Manchanda and K. C. Dash, Talanta, 1996, 43, 13051312.

18 J. M. Cleveland, in The Chemistry of Plutonium, Gordon and Breach Science Publishers, New York, 1970.

19 S. Panja, P. K. Mohapatra, P. Kandwal, S. C. Tripathi and V. K. Manchanda, Desalination, 2010, 262, 57-63.

20 R. B. Gujar, D. Shanthana Lakshmi, A. Figoli and P. K. Mohapatra, J. Chromatogr. A, 2013, 1305, 48-54.

21 P. Qu, H. Tang, Y. Gao, L. Zhang and S. Wang, BioResources, 2010, 5, 2323-2336.

22 P. K. Mohapatra and P. K. Khopkar, Polyhedron, 1989, 8, 2071-2076.

23 P. K. Mohapatra and V. K. Manchanda, J. Radioanal. Nucl. Chem. Art., 1992, 156, 215-221.

24 M. S. Caceci and G. R. Choppin, Radiochim. Acta, 1983, 33, 101-104.

25 H. Bessbousse, T. Rhlalou, J. F. Verchere and L. Lebrun, J. Phys. Chem. B, 2009, 113, 8588-8598.

26 K. R. Hall, L. C. Eagleton, A. Acrivos and T. Vermeulen, Ind. Eng. Chem. Fundam., 1966, 5, 212-223.

27 H. M. F. Freundlich, Z. Phys. Chem., 1906, 57, 385-470.

28 G. McKay, H. S. Blair and J. R. Garden, J. Appl. Polym. Sci., 1982, 27, 3043-3057.

29 M. M. Dubinin and L. V. Radushkevich, Proc. Acad. Sci. USSR, Phys. Chem. Sect., 1947, 55, 331-347.

30 M. Polanyi, Trans. Faraday Soc., 1932, 28, 316-333.

31 F. Helfferich, Ion Exchange, McGraw-Hill, New York, 1962. 